\title{
BIOLOGICAL EFFECT OF ACRYLAMIDE ON PAROTID SALIVARY GLAND OF ALBINO RATS
}

\author{
Rasha H. Al-Serwi*; Mohamed Mahmoud Anees ${ }^{* *}$ and Aya S. Abd Elhamied ${ }^{* * *}$
}

\begin{abstract}
Introduction : Nutrition is a very important environmental factor that plays a crucial role in short and long-term health outcomes. Findings of acrylamide in many starchy foods have increased the interest in understanding its toxic mechanisms and risks upon human.

Objective : This study aimed to clarify the biological effects of acrylamide intake on parotid salivary gland in albino rats structurally and ultra-structurally.

Methodology: Twenty male Wistar albino rats were randomly allocated into test and control groups. Group I (control group), were taking saline vehicle (4 rats). Group II (test group), were taking acrylamide in dose of $15 \mathrm{mg} / \mathrm{kg}$ and divided into two subgroups ( 8 rats for each). The parotid salivary gland biopsy was taken according to the experimental periods (A: 15 days; B: 30 days). At the respective monitoring periods, the parotid gland was dissected and prepared for histological examination and evaluated by morphometry to record the histologic changes and electron microscopic analysis.
\end{abstract}

Results: Light microscopic studies revealed degeneration, fusion and loss of acinar cells outlines, scattered cellular remnants throughout the gland, pyknotic nuclei, varying sizes of cytoplasmic vacuoles in the acinar cells and destruction in the duct outlines with loss of its cell lining which increased by time. Electron microscopic analysis showed pyknotic nuclei with abnormal dilatation and degeneration of cytoplasmic organelles (golgi complex, rough endoplasmic reticulum and mitochondria), many clearly evident cytoplasmic vacuoles and considerable numbers of immature electron-lucent granules of different shapes and size were detected which decreased with prolonged acrylamide intake. Differences in normal nuclear count, circulatory factor of serous acini and inter-connective tissue space in between the acini in both test and control groups were statistically calculated and were found to be significant. Group comparison at different time periods revealed, significant differences between I \& IIA, I \& IIB and IIA \& IIB for the tested parameters $(\mathrm{P}<0.001)$.

Conclusions : On the basis of the obtained results, we concluded that acrylamide intake yielded structural / ultra-structural changes of parotid salivary gland and the effects were pronounced with prolonged intake. This might indicate risk of gland damage due to acrylamide intake.

* Oral Biology Department, Faculty of Dentistry, Mansoura University, Egypt.

** Oral Medicine and Periodontology, Faculty of Dentistry, Mansoura University, Egypt.

*** Veterinary at Medical Experimental Research Center (MERC), Mansoura University, Egypt. 


\section{INTRODUCTION}

Evidence exists that some ingredients of foods can induce epigenetic phenomena in genotoxic and non-genotoxic ways, with long-term effects on human health. The short-term effects of harmful food components can cause structural damage and functional failure to various systems and organs resulting from the direct toxic tissue effects. ${ }^{(1)}$

Acrylamide (AA) is not present naturally, it was found in various deep-fried and oven-baked foods. It is related to foods that are regularly consumed throughout the years, as chips, bread, biscuits, crackers and breakfast cereals. ${ }^{(2)}$ It became of concern when it was discovered in heated food, formed by Maillard reaction which occurs between some amino acids and sugar during high temperature cooking processes. ${ }^{(3)} \mathrm{AA}$ is an unsaturated carbonyl compound with a high chemical activity. It is used in many fields from industrial manufacturing to laboratory personnel work; found to be absorbed during occupational exposure. ${ }^{(4)}$

The International Agency for Research on Cancer and the US Environmental Protection Agency classified acrylamide as a probable human carcinogen. ${ }^{(5)}$ According to Dybing et al., 6 of 10000 people will develop cancer as a result of ingesting acrylamide in food stuffs. ${ }^{(\boldsymbol{)})}$ Regarding humans, its consumption increased risks of renal, ovarian, endometrial, breast and oral cavity cancers. ${ }^{(7)}$ Oral administration of AA initiates sebaceous glands adenoma and squamous cell carcinoma in the skin and increases the incidence of adenomas and carcinoma of the lungs. ${ }^{(8)}$

The secretions of salivary glands are rich in fluids, ions and proteins important for the integrity of the teeth and oral health. ${ }^{(9)}$ Diet composition, taste and consistence causes alteration in the activity of salivary glands which can change salivary flow and composition. ${ }^{(10-12)}$

The activity and integrity of salivary glands should be evaluated according to effects of diet and nutrition. The findings in humans are markedly similar to the results of animal studies. Information from the animal model study is helpful for the understanding of the cellular gland alterations. The goal of the present study was to clarify the biological effect of acrylamide intake on parotid salivary gland in rats structurally and ultra-structurally.

\section{MATERIALS AND METHODS}

\section{Animal model}

All procedures were done according to the institutional standards for the use and care of experimental animals at the Medical Experimental Research Center (MERC), Mansoura University. Twenty male Wistar albino rats (200-250 g) were used for the study. Before the experiment, animals had been fed standard water, libitum and rat chow and housed in cages with temperature $22^{\circ} \mathrm{C}$ and 12hour light/dark cycle for 1 week.

\section{Drug administration}

Acrylamide (99.9 purity) was obtained from sigma chemical Co. Its molecular formula is C3 H5 NO. The applied dose of $15 \mathrm{mg} / \mathrm{kg}$ body weight (Lopachin et al., 2003) was dissolved in $0.2 \mathrm{ml}$ saline solution and given orally by gastric tube. ${ }^{(13)}$

\section{Experimental groups}

Rats were randomly allocated regarding to treatment received into : Group I (control group); were taking saline vehicle (4 rats). Group II (test group); were taking acrylamide $(15 \mathrm{mg} / \mathrm{kg})$ and were divided into two subgroups ( 8 rats for each). The parotid salivary gland biopsy were taken regarding to the experimental time periods [A: 15 days; B: 30 days].

\section{Dissection of the salivary gland}

At the monitoring periods, animals were chosen from each group and the rats were anesthetized then killed with over dosage of thiopental $(5 \mathrm{ml} / 100 \mathrm{~g})$ 
i.p. injection. Tissues were examined grossly and the parotid salivary gland of the right side was dissected into two halves, then samples were cut and prepared for fixation. Half of specimens were fixed using $10 \%$ formalin for 48 hours at $4{ }^{\circ} \mathrm{C}$, then embedded in paraffin and prepared for histological examination was done by light microscopy after sections were stained with haematoxylin and eosin.

\section{Transmission electron microscope preparations}

The other half of the specimens were dissected and cut into small pieces approximately $1 \mathrm{~mm}^{3}$ each, then immediately fixed in $1 \%$ glutaraldehyde for 2 hours, and processed to obtain Epon capsules. Semi thin sections approximately $1 \mu \mathrm{m}$ thickness were cut, stained with toluidine blue, and then examined using light microscope. Ultrathin sections (50-60 $\mathrm{nm}$ thick) were cut using a LKB ultramicrotome, then stained with uranyl acetate and lead citrate, and finally examined by Joel Transmission Electron Microscope in the Electron Microscopic Unit, Faculty of Medicine, Tanta University. ${ }^{(14)}$

\section{Computer assisted digital image analysis (Digital morphometric study)}

Slides were photographed by Olympus ${ }^{\circledR}$ digital camera installed on Olympus ${ }^{\circledR}$ microscope with $1 / 2 \mathrm{X}$ photo adaptor, using $40 \mathrm{X}$ objective . The resulting images were analyzed on Intel ${ }^{\circledR}$ Core $I 3 \AA$ computer by Video Test Morphology ${ }^{\circledR}$ software (Russia) with a specific routine for:

A. Object counting and analysis, nuclei were evaluated according to HSB ranges excluding abnormal ones depending on color intensity, circularity and size measurements.

B. Geometrical shape analysis, serous acini were manually selected and extracted using Genius G-Pen F509 digital tablet, the circularity factor of the selection was measured.

C. Area measurement, inter-connective tissue space in between serous acini was evaluated according to HSB ranges then, its area was measured.
Five slides from each case were prepared and 5 fields from each slides were checked randomly.

\section{Statistical Analysis}

Data were tabulated, coded and finally analyzed using the computer program SPSS 17. Descriptive statistics were calculated in the form of mean and standard deviation. The significance of difference was tested using ANOVA (analysis of variance) to compare between more than two groups of numerical (parametric) data. Statistically significant difference was considered at $\mathrm{P}$ value $<0.05$.

\section{RESULTS}

\section{Light microscopic findings}

Group I, showed acinar cells with narrow lumen and large basally located nuclei (Fig. 1A). While, group IIA showed degeneration of the acini with loss of cellular outlines with scattered cellular remnants throughout the gland, destruction in the duct outlines, pyknotic nuclei in addition to many acinar cells showing numerous cytoplasmic vacuoles of varying sizes (Fig. 1B). Group IIB showed homogenous fusion between acinar cells with absence of the lobular structure and extensive coarse vacuolization in the acinar cells which in some acinar cells displaced the nuclei from its original position.Loss of cell lining in the duct structure was noted (Fig.1C).

\section{Transmission electron microscope findings}

Group I showed serous cells of parotid gland containing euchromatic nuclei with homogenous secretory granules and narrow lumen (Fig. 2A). The mitochondria appeared with different shapes, condensed rough endoplasmic reticulum and golgi complex were clearly evident (Fig. 2B).

Group IIA, showed the nuclei with irregular margins, large immature electron-lucent granules predominated over the mature electron-dense granules and clear dilation in the cytoplasmic 
organelles clearly appeared (Fig.2C). Many cytoplasmic vacuoles were clearly seen, the mitochondria presented discontinuity in the parallelism of its crests and the golgi complex showed dilatation (Fig.2D).

Meanwhile group IIB, showed shirnked nuclei with loss of cytoplasmic organelles and decrease in the secretory granules both immature electronlucent granules and mature electron-dense granules (Fig.2E). Increase in the cytoplasmic vacuoles, widening and ballooning of the cisterns of the rough endoplasmic reticulum and swollen degenerated mitochondria (Fig.2F).

\section{Statistical results}

The results of the current study showed a statistically significant decrease in histological parameters of normal nuclei count, circulatory factor of serous acini and inter-connective tissue space in between those acini in test group than the control group. This decrease was significantly more in group IIB than group IIA (Table 1).

TABLE (1) Histological parameters in test and control groups:

\begin{tabular}{|c|c|c|c|c|c|c|c|}
\hline Histological parameters & \multicolumn{2}{|c|}{ Normal nuclei count } & \multicolumn{2}{|c|}{ Circularity factor of acini } & \multicolumn{2}{|c|}{ Intercellular space } & ANOVA \\
\hline Groups & Mean & $\pm \mathrm{SD}$ & Mean & $\pm \mathrm{SD}$ & Mean & $\pm \mathrm{SD}$ & \multirow{4}{*}{$<0.001$} \\
\hline Group I & $187.3^{\mathrm{a}}$ & 17.8 & $184.6^{\mathrm{a}}$ & 11.7 & $12.85^{\mathrm{a}}$ & 3.6 & \\
\hline Group IIA & $136.4^{\mathrm{b}}$ & 11.3 & $164.06^{b}$ & 9.7 & $7.03^{\mathrm{b}}$ & 1.6 & \\
\hline Group IIB & $113.6^{\mathrm{c}}$ & 9.84 & $141.3^{\mathrm{c}}$ & 12.3 & $1.039^{\mathrm{c}}$ & 0.34 & \\
\hline
\end{tabular}

\section{P: Probability test used: ANOVA $(P<0.05)$}

Different letters indicate significant difference: a) Significance between group I and group IIA. b) Significance between group I and group IIB. c) Significance between group IIA and group IIB.

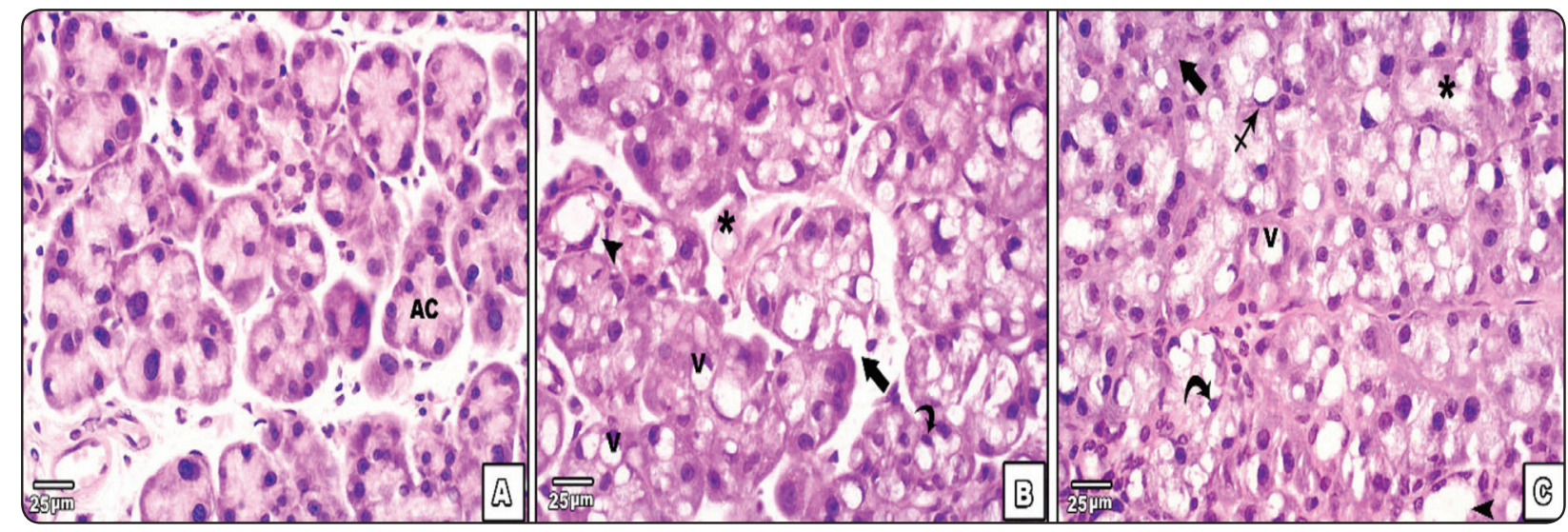

Fig. (1) Photomicrographs of the parotid gland showing: Fig. (A) Group I, showing acinar cells (AC) with narrow lumen and large basally located nuclei. Fig. (B) Group IIA, showing degeneration of the acini with loss of cells outlines (black arrow) and cellular remnants scattered throughout the gland (black asterisk). Pyknotic nuclei (curved black arrow) and numerous cytoplasmic vacuoles of varying sizes are seen in many acinar cells (V). Note destruction in the duct outlines (arrow head). Fig. (C) Group IIB, showing homogenous fusion between acinar cells with absence of the lobular structure (black arrow). Cellular remnants scattered throughout the gland (black asterisk). Pyknotic nuclei (curved black arrow) and extensive coarse vacuolization in the acinar cells (V) which in some acini displaced the nuclei from its original position (crossed arrow).Note, loss of cell lining in the duct structure (arrow head). (H\& E X 400) 

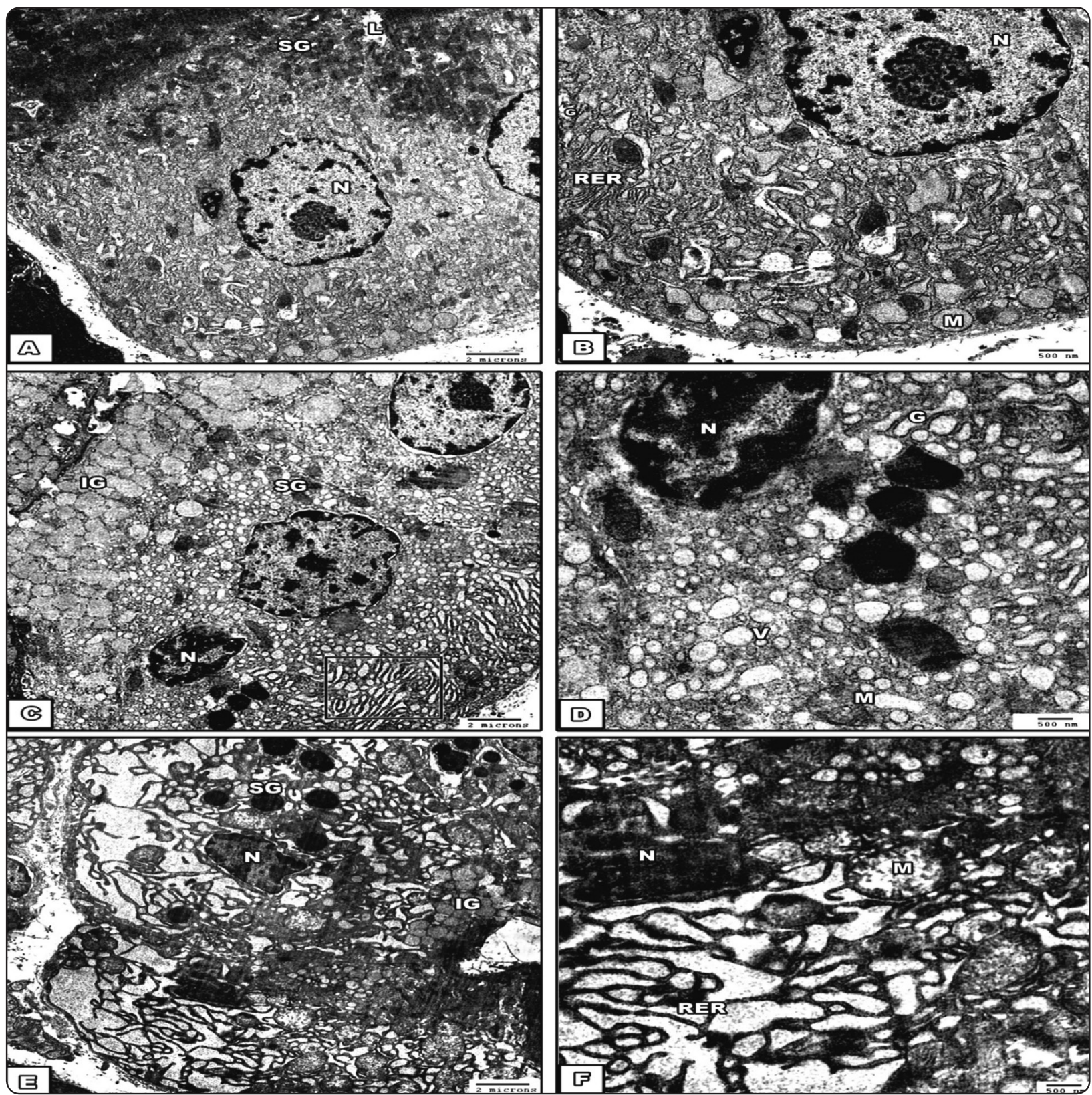

Fig. (2) Electron micrographs of the parotid gland showing: Fig. (A) Group I showing serous cells of parotid gland containing euchromatic nuclei (N) with homogenous secretory granules (SG) and narrow lumen (L) (X500). (B)Higher magnification of the pervious one showing mitochondria (M) with different shapes, condensed rough endoplasmic reticulum (RER)and the golgi complex (G) (x4000) (C) Group IIA, showing nuclei (N) with irregular margins. Secretory granules clearly appears with large immature electronlucent granules (IG) predominant over the mature electrondense granules (SG). Dilation in the cytoplasmic organelles clearly appeared (squared area) (X1500) (D) Higher magnification of the pervious one showing many cytoplasmic vacuoles (V). The mitochondria presenting discontinuity in the parallelism of its crests (M). The golgi complex showing dilatation (G). (X4000) (E) Group IIB, showing shirnked nuclei (N) and loss of cytoplasmic organelles. Decrease in the secretory granules both immature electronlucent granules (IG) and mature electrondense granules (SG). (X1500) (F)Higher magnification of the pervious one showing many cytoplasmic vacuoles (V). Widening and ballooning of the cisterns of the rough endoplasmic reticulum (RER) and swollen degenerated mitochondria (M). (X4000) 


\section{DISCUSSION}

Nutrition is the most important environmental factor that has a crucial role in short and long-term health consequences. ${ }^{(15)}$ Findings of acrylamide in many common starchy foods have elicited the interest in evaluating its toxic mechanism and recognize its risks on humans. ${ }^{(16)}$

When acrylamide is taken orally, it passes the gastrointestinal barrier by passive diffusion, so a high bioavailability can be present in the circulatory system. ${ }^{(17)}$ Acrylamide can reach each organ and all tissues in the body because its molecule is small and hydrophilic. ${ }^{(18)}$ Consequently, all tissues may be susceptible targets for its toxicity.

Depending upon the above concepts, the present work aimed to elucidate the biological effect of acrylamide intake along different durations on parotid salivary gland in Wistar albino rats. Light and electron microscopic examinations of the parotid salivary glands were performed and evaluated by morphometry to record the histologic changes.

There are limited studies in the literature concerning the structural and ultrastructural effects of acrylamide on salivary glands, thus the findings of this study can only be compared to acrylamide effect upon other different tissues.

In the current study light microscopic and electron microscopic findings of group I (control group) revealed large extent to its corresponding on parotid salivary gland structure which was done in researches on rodents and other mammals. ${ }^{(19,20)}$

After acrylamide ingestion for 15 days, group IIA showed pyknotic nuclei, vacuolization in the acinar cells and loss of acinar cells outlines with cellular remnants scattered throughout the gland. In an attempt to find an explanation for the histological changes at the light microscopic level; normal nuclei count, circulatory factor of the serous acini and intercellular space were measured in tissue sample of the parotid salivary glands. The above mentioned histological parameters showed statistically significant decrease in rats exposed to acrylamide for 15 days versus the control group. This result is analogous in many respects to pervious research done on the liver and kidneys in albino rats treated with acrylamide. ${ }^{(21)}$

The ultrastructural findings of group IIA showed clear signs of degeneration; dilation in the cytoplasmic organelles and irregular margins of nuclei. These degenerated or irregular shaped nuclei might also explain the decrease in the normal nuclear count in the statistical outcomes. Nunes et al. studied morphological, histological, and ultrastructural characterization of degenerating salivary glands found out the same histologic features as has been show in the result of this study. ${ }^{(22)}$

Similarly, Sahai et al. in his research carried on mice which were treated at a dose of $10 \mathrm{mg} \backslash \mathrm{kg}$ of acrylamide for 10 days in drinking water found a histopathological changes in liver hepatocytes and disorganization of lobules. There were also significant changes and decrease in the number of hepatocytes. ${ }^{(23)}$ In the present study, the significant decrease in the circulatory factor of the acini and the inter connective tissue space in between them might be considered as histopathological changes and disorganization in these acini.

The results of the present study were in contrast with the findings of Khan et al., who did not found any effect of acrylamide on the histology of thyroid gland morphology after acute acrylamide exposure. (24) The reported differences may be attributed to different tissue reaction. ${ }^{(25)}$ In another study done by Abd El-Mottaleb who done some studies on acrylamide intoxication in male albino rats proved that the most affected organs were brain, glands and testes beside the parenchymatous organs. ${ }^{(26)}$

Acrylamide intake for 30 days (group IIB), Homogenous fusion between acinar cells with absence of the lobular structure and extensive coarse 
vacuolization. Such pathologic features were seen in the hepatic parenchyma in rats received $30 \mathrm{mg} / \mathrm{kg}$ of acrylamide. ${ }^{(27)}$ Cheville added that these vacuoles are responsible for collecting the injurious elements and preventing them from interfering with the biological activities of these cells. ${ }^{(28)}$

Moreover, the normal nuclear count, circulatory factor of the serous acini and intercellular space were significantly decreased more in rats exposed to acrylamide treated for 30 days than those treated for 15 days. These findings which might be due to the toxicity of long-term acrylamide has been well documented researches on experimental animals. ${ }^{(29,30)}$

Ultrastructural analysis of group IIB showed shirnked nuclei with loss of cytoplasmic organelles, cytoplasmic vacuoles, widening and ballooning of the cisterns of the rough endoplasmic reticulum in addition to swollen degenerated mitochondria. As appeared in the present study the exposure to acrylamide turned the degenerative changes into necrotic damage, and tissue lysis.

This coincide with the findings of other study, hypertrophy of the cytoplasmic organelles and pyknotic nuclei were seen in acrylamide treated chick. ${ }^{(31)}$ Stadleret al., also suggested that acrylamide increases the cellular destructed lysosomes that facilitate the process of autolysis which was confirmed this current work ${ }^{(32)}$ The nuclear damage as a sequence of cytoplasmic damage in work done by Abdel Hameed was also detected in the present study. ${ }^{(33)}$

The acrylamide toxicity was explained by Odland et al. through its metabolic pathway, so conjugation of glutathione catalyzed by glutathioneS-transferase(GSH) results in the formation of mercapturic acid which is the major pathway for acrylamide metabolism. The marcapturic acid is toxic and usually excreted in the human's and animal's urine. ${ }^{(34,35)}$
In the present study, toxic marcapturic acid and the depletion in GSH mentioned by Wu YQ et al. might be the causes of reduced protection of cell membrane to oxidative stress study ${ }^{(36)}$ which might explain the signs of salivary gland degeneration and necrosis.

On the basis of the present study, we concluded that acrylamide intake yielded structural/ ultrastructural changes of parotid salivary glands and the effects were aggravated with prolonged intake. This would indicate risk of the gland damage due to acrylamide intake.

\section{RECOMMENDATION}

It is recommended that food safety authorities apply practical measures to reduce acrylamide formation in susceptible foods in order to decrease human exposure to it.

\section{ACKNOWLEDGMENT}

We gratefully acknowledge Prof. Dr. Manal I. Elnouaem Prof. of Oral Pathology, Faculty of Dentistry, Alexandria University for her help, effort and revision of this research.

\section{REFERENCES}

1. Koletzko B, Koletzko S, Ruemmele F. Drivers of innovation in pediatric nutrition. Preface. Nestle Nutr Workshop SerPediatrProgramme 2010; 66: VII-VIII.

2. Brathen E, Knutsen SH, Brathen E and Knutsen SH, Effect oftemperature and time on the formation of acrylamide in starch-basedandcerealmodel systems, flat breads and bread. FoodChem 2005;2(4):693-700.

3. Mottram DS, Wedzicha BL and Dodson AT. Acrylamideisformed in the maillard reaction. Nature 2002; 419(6909):448-449.

4. Boettcher MI, Schettgen T, Kütting B, Pitschetsrieder M and Angerer J. Mercapturic acids of acrylamide and glycidamide as biomarkers of the internal exposure to acrylamide in the general population. Mutat Res 2005; 580: 167-176. 
5. US Environmental Protection Agency, 1994. Acrylamide. IARC Monogr. Eval.Carcinog. Risks Hum. 60, 389-433.

6. Dybing E, Farmer PB, Andersen M, Fennell TR, Lalljie SP, Muller DJ, Olin S, Petersen BJ, Schlatter J, Scholz G, Scimeca JA, Slimani N,Tornqvist M, Tuijtelaars S and Verger P. Human exposure and internal dose assessments of acrylamide in food. Food ChemToxicol 2005; 43(3):365-410.

7. Hogervorst JG, Baars BJ, Schouten LJ, Konings EJ , Goldbohm RA and van den Brandt PA. The carcinogenicity of dietary acrylamide intake: a comparative discussion of epidemiological and experimental animal research. Crit Rev Toxicol, 2010; 40(6)485-512.

8. Bull RJ, Robinson M, Laurie RD, Stoner GD, Greisiger E, Meier JR and Stober J. Carcinogenic effects of acrylamide in Sencar and A/J mice. Cancer Res, 1984a; 44(1):107111.

9. Leone CW and Oppenheim FG.Physical and chemical aspects of saliva as indicators of risk for dental caries in humans. J Dent Edu 2001; 65(10):1054-1062.

10. Johnson DA. Effects of diet and nutrition on the composition of saliva. In: Bowen WH and Tabak LA (Editors). Cariology for the nineties. Rochester, NY: University of Rochester Press. 1993; 367-381.

11. Lenander-Lumikari M, Loimaranta V. Saliva and dental caries. Adv Dent Res 2000; 14:40-47.

12. Sweeny EA. Salivary flow and composition in relation to dental caries.Methods and problems in studying this relationship. In: Proceedings and Dental Caries. Kleinberg I, Ellison SA, Mandel ID. Eds. New York: Information Retrieval; 1979. p 183.

13. Lopachin RM, Balaban CD and Ross JF. Acrylamideaxonopathy revisited. Toxicol. Appl. Pharmacol., 2003; 188(3); 135-153.

14. Macmillan Press. Principles of tissue preparation for electron microscopy. In Basic Techniques for Transmission Electron Microscopy (first ed.). New York (1986); Chapter2:22-46.

15. Furmaga-Jabłoñska W, Jabłoñski $M$ and Pluta R. A new polemic to acrylamide toxicity Nutrition 2012; 28(4):426427.

16. Doerge DR, Young JF, McDaniel LP, Twaddle NC and Churchwell MI. Toxicokinetics of acrylamide and glycidamide in B6C3F1 mice. Toxicology and Applied Pharmacology 2005; 202(3):258-267.

17. Schabacker J, Schwend T and Wink M. Reduction of acrylamide uptake bydietary proteins in a Caco-2 gut model. J Agric Food Chem 2004; 52(12):4021-4025.

18. Friedman M. Chemistry, biochemistry, and safety of acrylamide. A review. J Agric Food Chem 2003; 51(16):45044526.

19. Leal SC, Toledo OA and Bezerra AC. Morphological alterations of the parotid gland of rats maintained on a liquid diet.Braz Dent J. 2003; 14(3):172-176.

20. Younis RE, AbouElkhier MT, Mourad MI and Elnahas W. Ultrastructural changes in the parotid gland of rats after intraglandular injection of botulinum toxin A. Annals of Oral \& Maxillofacial Surgery 2013;1(4):38.

21. Mahmood SAF, Amin KAM and Salih SFM. Effect of Acrylamide on Liver and Kidneys in Albino Wistar Rats. Int.J.Curr.Microbiol.App.Sci (2015) 4(5): 434-444

22. Nunes ET, Bechara GH, Saito KC, Denardi SE, Oliveira PR, Mathias MIC. Morphological, histological, and ultrastructural characterization of degenerating salivary glands in females of the cattle-tick Rhipicephalus (Boophilus) microplus (CANESTRINI, 1887) (Acari: Ixodidae).Micron $2005 ; 36(5): 437-447$.

23. Sahai V. Histological changes in liver of albino mice due to chronic administration of acrylamide. Indian Journal of Fundamental and Applied Life Sciences 2012; 2(3):51-54.

24. Khan MA, Davis CA, Foley GL, Friedman MA and Hansen LG. Changes in thyroid gland morphology after acute acrylamide exposure. Toxicological Sciences 1999; 47(2):151-157.

25. Vescio RA, Connors KM, Kubota T and Hoffman RM. Correlation of histology and drug response of human tumors grown in native-state three-dimensional histoculture and in nude mice. Proc Natl Acad Sci U S A. 1991; 88(12):5163-5166.

26. Abd El-Mottaleb EM and Rashed AYM. Some studies on acrylamide intoxication in male albino rats. Egypt $\mathrm{J}$. Comp Path \& Clinic Path 2008;21(4):222 - 245.

27. AL-Mosaibih MA. Effects of monosodium glutamate and acrylamide on the liver tissue of adult wistar rats. Life Science Journal 2013;10(2s):35-42. 
28. Cheville, N.F. Response to Cellular Injury. In Ultrastructural pathology the comparative cellular basis of disease. 2nd ed. DEC 2009; Chapter $1: 3-31$.

29. Friedman MA, Dulak LH, Stedham MA. A lifetime oncogenicity study in rats with acrylamide. Fundam Appl Toxicol. 1995; 27(1):95-105.

30. Johnson KA, Gorzinski SJ, Bodner KM, Campbell RA, Wolf CH, Friedman MA, Mast RW. Chronic toxicity and oncogenicity study on acrylamide incorporated in the drinking water of Fischer 344 rats. Toxicol Appl Pharmacol 1986; 85(2):154-168.

31. Kedam TR, Sheik R.B, Bai MM, and Haseena Bhanu, SK. A histological study on acrylamide and cadmium chloride altered chick embryonic liver. IOSR Journal of Pharmacy 2012;2(1): 001-008.

32. Stadler RH, Blank I, Varga N, Robert F, Hau J, Guy PA, Robert MC, Riediker S. Acrylamide from maillard reaction products. Nature 2002; 419(6906):449-450.

33. Abdel Hameed TF. Light and electron microscopic studies on the effect of orally administered formalin on liver and kidney of guinea pig. Journal of the Egyptian German Society of Zoology C. Histology and Histochemistry 2004;45 (c):203-224.

34. Odland I, Romert L, Clemedson C and Walum E. Glutathione content, glutathione transferase activity and lipid peroxidation in acrylamide-treated neuroblastoma NIE 115 cells.Toxicol.In vitro 1994;8(2): 263-267.

35. Chatterjea MN and Shinde . Detoxication. In text Book of Medical Biochemistry, 7th ed. New Delhi , 2007; Chapter 32:517-523.

36. Wu YQ, Yu AR, Tang XY, Zhang J and Cui T. Determination of acrylamide metabolite, mercapturic acid by high performance liquid chromatography. Biomed. Environ. Sci. 1993; 6(3):273-280. 